\title{
Digitalization of the Largest Russian Cities: Strategic Priorities of Research and Innovative Development
}

\author{
Ivan Antipin ${ }^{1, *}$ Natalia Vlasova ${ }^{1}$ Vasa László ${ }^{2}$
}

\author{
${ }^{1}$ Ural State University of Economics \\ ${ }^{2}$ Szechenyi Istvan University, Hungary \\ *Corresponding author.Email: aia87@mail.ru
}

\begin{abstract}
The article discusses priorities of research and innovative development of Russian regional capitals - the largest cities. This topic is particularly important in the current Russian context: regional capitals, being actively involved in globalization processes, need to enhance their competitive edge and adopt new digital technologies in order to respond effectively to global challenges. The article compares the largest cities' socio-economic performance and assesses their technological development and readiness for digital transformation. The article also provides a comprehensive analysis of strategic planning documents and strategic priorities of Russian regional capitals. As a result, considerable contradictions and discrepancies, which threaten the successful implementation of these strategies, are revealed. The guidelines for priority setting formulated by the authors focus on innovation, research and digitalization. These guidelines were tested in Ekaterinburg, the administrative centre of Sverdlovsk region. A set of programs and projects is also proposed to enhance the technological development of Ekaterinburg and help it keep up with the current global trends, primarily digitalization. The authors also provide rationale for the goals, targets and objectives pursued by these programs and projects.
\end{abstract}

Keywords: Strategic Planning, Largest City, Smart City, Smart Governance, Innovation, Digitalization.

\section{INTRODUCTION}

At the beginning of the twenty-first century, Russian economy had to face such long-term systemic challenges as the increasing worldwide competition. To achieve a major breakthrough in the country's technological and socio-economic development, the government set the national goals to be reached until 2024. ${ }^{1}$ In 2017, two other documents were adopted: the 'Strategy of Development of Information Society in the Russian Federation for 2017-2030' ${ }^{2}$ and the state program 'Digital Economy in the Russian Federation'. ${ }^{3}$

\footnotetext{
${ }^{1}$ On National and Strategic Goals of Development of the Russian Federation Until 2024: Decree of the President of the Russian Federation of 07.05.2018 №204 [Electronic resource]. - Access mode: - Legal reference system 'Konsultant Plus'.

2 On the Strategy of Development of Information Society in the Russian Federation for 2017-2030: Decree of the President of the Russian Federation of 09.05.2017 №203 [Electronic resource]. URL:
}

New digital technologies transform all spheres of social life, these processes being especially pronounced in the largest and big cities as they reshape governance, planning and city management and change priorities of urban development.

Strategic priorities and goals of the largest Russian cities were discussed, and guidelines were proposed for relevant programs and projects that will allow these cities to more effectively solve the problems of digitalization.

Therefore, we are going to analyze priorities of technological development described in the main strategic planning documents of the largest Russian

http://www.consultant.ru/document/cons_doc_LAW_216363/ (last accessed date: 28.01.2019).

${ }^{3}$ On the Program 'Digital Economy in the Russian Federation': Decree of the President of the Russian Federation of 28.07.2017 № 1632-p [Electronic resource]. -URL: http://government.ru/docs/28653/ (last accessed date: 28.01.2019). 
cities; investigate the core indicators that reflect socioeconomic development of such cities and rank these cities according to their competitiveness; and, finally, propose a set of programs and projects that could be used to stimulate research and innovation in these cities in the context of digitalization processes.

The analysis focused on the main stages of the strategic planning cycle:

- $\quad$ analysis of the internal and external environment;

- goal-setting (mission, general aim, system of goals ('goal tree'));

- $\quad$ strategy building (strategy structure) - priorities, programs, projects, and so on;

- framework and tools for strategy implementation;

- $\quad$ monitoring system.

\section{METHODOLOGY}

Innovative development is a key area of strategic development of modern cities. Although the research into the role of cities as innovation centres has quite a long history [1], at its current stage the main focus is placed on strategies of innovative development necessary to ensure the cities' competitive advantage on the global arena.

As technology and innovation are seen as a major driving force for development in the modern world, there is a particular focus on innovative development in the strategic vision for many cities.

For example, the analysis of characteristics shared by 15 'smart cities' demonstrated that the majority of the strategies highlighted the role of information and communication technologies for improvement of urban systems as well as the importance of knowledge transfer and innovation networks. In many studies, however, no detailed information is provided as to what are the key mechanisms behind these improvements. Such mechanisms may include, for example, 'bottom-up' approaches, which help the government consider local needs and allow for more citizen participation for greater stability and sustainability of the system [2].

The main global trends include new industrialization, Industry 4.0, and digital economy. One of the essential elements of Industry 4.0 is the 'internet of things' (IoT). Some scholars distinguish between the 'internet of things' and the 'internet of services', pointing out that the latter comprises such spheres as smart transport and logistics, and the 'internet of energy' [3].
Industry 4.0 implies a radical change brought about by automated workflow and digitalization of manufacturing processes and the transfer from the 'internet of people' to 'the internet of things' [4]. Apart from technical innovation, the concepts of Industry 4.0 and the IoT also encompass other spheres of life, including social relations, consumption, safety and so on. [5].

Many scholars highlight the connection between the IoT and the 'smart city' [6]. The latter is characterized by a high level of integration of information technologies and integrated use of information resources. Albino, V., Berardi, U., Dangelico R.M. provide a comprehensive review of approaches to the definition of 'smart city' in contemporary research literature and official documents. They also identify the key characteristics of the smart city [7].

The IoT's explosive growth creates a number of research and engineering problems, which require new approaches in urban planning and governance [8, 9]. In order to tackle the associated risks and not to miss any valuable opportunities, city strategies must address all the key modern trends. The largest cities should be able to capture the benefits of technological progress and fulfil their role as pioneers of innovation, which is particularly important at this stage because in the future, countries' competitive edge will largely depend on that of their major cities. Furthermore, being a quintessentially complex system, a largest city concentrates processes and activities that are increasingly shaped by new technologies. The introduction of smart city technologies determines the priority of the development of high-tech industries as the engines of the urban economy and relies on technological tools to solve urban problems. This can lead to a tendency to exclude people from the management decision-making system, and can also strengthen control functions [10].

'Smart city' governance predominantly relies on efficient interactions between stakeholders on all levels of internal and external environment: for example, between national government bodies and non-governmental organizations [11]. As international experience has shown, the IoT radically transforms urban environment, including the system of city management [12]. Millions of various systems are now connected to the Internet and their work should be well coordinated, which means new challenges for 
security management services. Moreover, this process is much more intensive than the technological processes of the previous innovation cycles. Large
At the current stage, many Russian scholars discuss urban strategic development in the light of digitalization, which is seen as related to such

Table 1. The largest Russian cities

\begin{tabular}{|l|c|l|}
\hline City & $\begin{array}{c}\text { Population, thousands } \\
01.01 .2020\end{array}$ & Date of Strategy approval \\
\hline Chelyabinsk & 1196680 & November 26, 2009 \\
\hline Ekaterinburg & 1493749 & May 25, 2018 \\
\hline Kazan & 1257391 & December 14, 2016 \\
\hline Krasnoyarsk & 1093771 & June 18, 2019 \\
\hline Nizhny Novgorod & 1252236 & January 25, 2017 \\
\hline Novosibirsk & 1625631 & December 24, 2018 \\
\hline Omsk & 1154507 & July 09, 2014 \\
\hline Perm & 1055397 & April 22, 2014 \\
\hline Rostov-on-Don & 1137904 & December 18, 2012 \\
\hline Samara & 1156659 & September 26, 2013 \\
\hline Ufa & 1128787 & December 19, 2018 \\
\hline Volgograd & 1008998 & January 25, 2017 \\
\hline Voronezh & 1058261 & December 19, 2018 \\
\hline
\end{tabular}

Source. Compiled by the authors. The data covers all Russian million-plus cities, except for Ufa, whose strategy has not been approved yet and, therefore, has not been made publicly available

amounts of data need to be processed and analyzed, therefore, urban planning and management now requires the use of big data databases [13]. Babar, $\mathrm{M}$. and Arif, F. use big data analysis and describe the new principles and new architecture for managing 'smart cities' [14]. Therefore, strategies for the development of large modern cities are bound to include such terms as 'smart city, 'digital economy', 'IoT', 'big data', and 'big data databases' $[15,16]$.

'Digital economy' and 'digitalization' are the new 'buzz terms' widely used in different contexts, which makes their meanings somewhat ambiguous. Digital economy could be consider as a communication environment for economic activity in the Internet and forms, instruments and outcomes of its realization. We endorse the position scholars, who maintains that there are two main approaches to defining the term 'digital economy'. Within the first, 'classical' approach, digital economy is considered as a type of economy based on digital technologies. It would be more accurate to say that digital economy deals exclusively with electronic commodities and services such as telemedicine, elearning, sales of media content, and so on. According to the second, wider approach, 'digital economy' is a kind of economic production involving digital technologies [17].

As urban economy undergoes major structural changes associated with digitalization processes, the urban governance and planning system needs a deep transformation $[18,19]$. questions as forecasting [20], strategic planning and governance $[21,22]$.

\section{RESULTS AND DISCUSSION}

\subsection{Strategic Priorities of Research and} Innovative Development of the Largest Russian Cities

The largest cities, industrial, economic and political centres of Russian regions, are among the major drivers of national economy. There are 13 such cities in Russian Federation (Table 1). We did not include Moscow and St. Petersburg, as these cities have a particular status of a subject of the Russian Federation and their population significantly exceeds the number of other largest cities.

The largest cities' commitment to innovation and technological progress declared in their strategies is not always consistent with what is found on other levels of strategic planning. In order to determine whether the concepts of innovation and digitalization are represented in the strategic plans of the largest cities, we conducted a content analysis of the strategic plans of the largest Ural cities-Chelyabinsk, Yekaterinburg and Perm. We found out how often such terms as innovation, Smart City, Industry 4.0, IoT, Digital economy and other related terms are used (Table 2).

For instance, there are no terms 'smart city', 'Industry 4.0 ' or 'new industrialization' in the new 
version of Ekaterinburg's strategic plan. Nevertheless, the section 'Ekaterinburg as a new interregional innovation-oriented industrial and financial centre' describes the city's gradual transition to smart urban infrastructure, in particular, application of IoTenabling technologies in managing urban processes, and implementation of the 'Digital economy' government program.

The Strategy of Socio-Economic Development of the Municipality of Perm contains part 2.1 "New Economy: Knowledge-based economy", but the text does not contain terms related to the digital economy, "Internet of Things" and so on.

Strategy of Development of Chelyabinsk until 2020 points to the need to solve the problems of international competition and choose the optimal long-term strategy for the city development. However, the strategy itself does not mention any important trends related to the digitalization of the economy or IoT.

\subsection{Mechanisms and tools of research and} innovative development of Ekaterinburg

In this part, we focused on the specific framework and tools that could be applied to ensure Ekaterinburg technological development. The key strategic area for Ekaterinburg's development should be its transformation into a interregional centre of 'new economy', capable of participating in global economic processes. This aim can be achieved by enhancing the city's competitive edge in industrial and financial spheres and by providing favourable conditions for sustainable development of innovation-driven business and investment. The following strategic programs will contribute to achieving the goals of the city innovative development:

\subsubsection{The program 'Ekaterinburg as a Centre of Industrial Innovation' (strategic goal 1) pursues the} following objectives:

attract investment to develop the city's industry and related spheres;

develop a comprehensive system of innovation and high-tech business support;

facilitate intracity and regional cooperation between large, medium and small production enterprises and research organizations;

foster the development of small and medium-sized high-tech enterprises and help them enter Russian and international markets; establish and develop compact industrial zones within the city and around it;

stimulate industrial modernization of the city;

Table 2. Frequency of term usage in the strategies of the largest Urals cities

\begin{tabular}{|l|c|c|c|}
\hline \multicolumn{1}{|c|}{ Terms } & Ekaterinburg & Chelyabinsk & Perm \\
\hline $\begin{array}{l}\text { Innovative } \\
\text { (development, } \\
\text { economy, activity, } \\
\text { and so on) }\end{array}$ & 36 & 18 & 30 \\
\hline $\begin{array}{l}\text { Information } \\
\text { (processes, } \\
\text { technologies, } \\
\text { systems, and so } \\
\text { on) }\end{array}$ & 6 & 1 & - \\
\hline $\begin{array}{l}\text { Digital (economy, } \\
\text { technologies) }\end{array}$ & - & - & - \\
\hline Big data & 2 & - & - \\
\hline Smart city & 1 & - & - \\
\hline Internet of things & - & - & - \\
\hline Industry 4.0 & - & - & - \\
\hline $\begin{array}{l}\text { New } \\
\text { industrialization }\end{array}$ & 36 & 18 & 30 \\
\hline
\end{tabular}

promote energy- and resource-saving technologies in industrial production;

support high-tech and innovative companies in patenting, homologation, standardization, and certification of their products and services according to international standards by covering some of the costs;

cooperate with regional and federal export institutions to assist industrial enterprises in their export activities.

This strategic program comprises strategic projects 'Hi-Tech Industry' and 'Innovative ventures'.

3.2.2. The program 'Ekaterinburg as an Interregional Financial and Investment Centre' (strategic goal 2) pursues the following objectives:

improve the system of support for investment projects and provide instruments of investment support;

enhance entrepreneurship competence, especially in the sphere of investment project design and implementation;

increase investment attractiveness of the city;

search for institutional investors (domestic and international) to realize large-scale infrastructural and innovation projects; 
Table 3. Expected outcomes of the strategic program 'Digital Ekaterinburg'

\begin{tabular}{|c|c|c|c|c|c|}
\hline \multirow[t]{3}{*}{ Indicator } & \multicolumn{4}{|c|}{ Stages of Strategy Implementation } & \multirow{3}{*}{ for 2035} \\
\hline & \multicolumn{4}{|c|}{$2021-2025 \quad 2026-2030$} & \\
\hline & $\min$ & $\max$ & $\min$ & $\max$ & \\
\hline $\begin{array}{l}\text { Share of households with the broadband Internet access, } \\
\text { of the total number of households (as of the end of the } \\
\text { period), \% }\end{array}$ & 93 & 97 & 96 & 98 & 99 \\
\hline $\begin{array}{l}\text { External internet traffic (inbound and outbound), involving } \\
\text { the use of modern information and telecommunication } \\
\text { systems (corporate network traffic is not considered), } \\
\text { Terabyte }\end{array}$ & 210 & 300 & 250 & 350 & 500 \\
\hline $\begin{array}{l}\text { Share of services provided by municipal authorities on- } \\
\text { line through the Public Services Portal and the official } \\
\text { web-site of the city's administration, of the total amount of } \\
\text { services provided by municipal authorities, \% }\end{array}$ & 57 & 60 & 60 & 64 & 67 \\
\hline $\begin{array}{l}\text { The share of on-line applications for municipal (state) } \\
\text { services, of the total number of applications, \% }\end{array}$ & 10 & 11 & 11 & 12 & 15 \\
\hline $\begin{array}{l}\text { The share of IT specialists (university graduates and } \\
\text { those who underwent professional retraining and } \\
\text { advanced training at universities), of the total number of } \\
\text { university-trained specialists, \% }\end{array}$ & 5 & 5.5 & 6 & 6.5 & 7 \\
\hline
\end{tabular}

develop the city's business and financial infrastructure and raise the status of the city as a regional decision-making centre.

This strategic program comprises strategic projects 'Financial Centre of the Urals' and 'Centre for Efficient Investment'.

\subsubsection{The program 'Digital Ekaterinburg' (strategic goal 3) pursues the following objectives:}

create conditions for developing advanced information and communication services, including mobile communications;

optimize communication infrastructure and information exchange between the administration, business and the public;

facilitate public access to information about the available support programs for entrepreneurs and investors;

implement the key areas of the state program 'Digital Economy', ensure balanced transition to 'smart' urban infrastructure, in particular, service management; stimulate application of IoT technologies in urban processes;

support the development of digital market niches; popularize and support small and medium-sized enterprises;

ensure business information security; and provide opportunities for employee training and retraining in the sphere of digital economy and information security.

This strategic program includes projects 'Modern Information Environment' and 'IT-Cluster'.

Table 3 illustrates performance indicators for each strategic area and their predicted values (Table 3 ).

The above-described strategy was tested in Ekaterinburg and we believe that it can be applicable for priority setting in any largest city.

\section{CONCLUSION}

One of the key priorities in the strategic development of the largest Russian cities and the whole country is technological and innovative development, especially in the socio-economic sphere, which means creating comfortable living conditions for urban dwellers and offer them ample opportunities for self-realization.

Digital economy or digitalization is thus seen as one of the main instruments of the largest cities' strategic development.

Well-conceived, clear vision lies at the core of efficient urban management, which requires careful strategic planning, priority- and goal-setting, effective implementation tools. Strategic planning and governance provide high rates of urban development 
and make the city more competitive in the national and global arena.

Unfortunately, current strategies of the largest Russian cities are lagging behind global trends and need to be updated to help the cities unlock their potential as major engines of growth.

The experience of Ekaterinburg can be used for strategizing the technological and innovative development of other largest cities (regional capitals). Ekaterinburg's strategic plan outlines the general vision of its development; it also describes its strategic priorities and correspondingly groups its specific goals, which are to be pursued through relevant programs and projects and subsequently controlled with pre-set indicators. In other words, it is a universal tool that can be used in the strategic planning system of any large city.

To address long-term systemic challenges and meet national development goals it is crucial to have a clear understanding of what the main strategic priorities should be and how they are implemented.

Russia's largest cities were pioneers in developing strategic development plans. Priorities described in these documents were re-shaped by the changes in stakeholders' interests and the objective processes of the country's economic and political development. Analysis of the strategic development priorities of Russia's largest cities shows that they do not always take into account current trends, which can significantly affect the level of competitiveness of these cities in the future. The above-described programs and projects can be used to stimulate technological development of any large city and enable it to meet the challenges of digitalization.

Strategic planning are crucial tool for efficient cooperation between all stakeholders. The outcomes of socio-economic development on various levels, including big cities, largely stem from adequate prioritization, implementation, and control.

\section{ACKNOWLEDGMENTS}

The article was prepared with the financial support of the RFBR of the research project No. 20-010-00824 "Incremental approach to the formation and implementation of socio-economic development strategies for the Russian Federation regions of different hierarchical levels: uniform rules of strategizing".

\section{REFERENCES}

[1] T. Hagerstrand, Innovation Diffusion as a Spatial Process. Chicago Univ, 1967.
[2] M. Angelidou, The role of smart city characteristics in the plans of fifteen cities, Journal of Urban Technology 24(4) (2017) 3-28. DOI:

https://doi.org/10.1080/10630732.2017.1348880

[3] M. Lom, O. Pribyl, M. Svitek, Industry 4.0 as a part of smart cities, Smart Cities Symposium Prague (SCSP), Prague (2016) 1-6. DOI: 10.1109/SCSP.2016.7501015

[4] T. H. Kim, C. Ramos, S. Mohammed, Smart city and IoT, Future Generation Computer Systems 76 (2017) 159-162. DOI: https://doi.org/10.1016/j.future.2017.03.034

[5] R. Morrar, H. Arman, S. Mousa, The Fourth Industrial Revolution (Industry 4.0): A Social Innovation Perspective, Technology Innovation Management Review 7(11) (2017) 12-20 DOI: http://doi.org/10.22215/timreview/1117

[6] I. Turgel, A. Panzabekova, Z. Satpayeva, Comparative analysis of approaches to designing of regulatory impact assessment institute in Russia, Kazakhstan, and Kyrgyzstan, Bulletin of National Academy of Sciences of the Republic of Kazakhstan 4 (374) (2018) 153 - 160.

[7] V. Albino, U. Berardi, R. M. Dangelico, Smart cities: Definitions, dimensions, performance, and initiatives, Journal of Urban Technology 22(1) (2015) 3-21. DOI: http://dx.doi.org/10.1080/10630732.2014.94209 2

[8] S. Barns, E. Cosgrave, M. Acuto, D. Mcneill, Digital infrastructures and urban governance, Urban Policy and Research 35(1) (2017) 20-31. DOI:

https://doi.org/10.1080/08111146.2016.1235032

[9] G. Viale Pereira, M. A. Cunha, T. J. Lampoltshammer, P.Parycek, M. G. Testa, Increasing collaboration and participation in smart city governance: a cross-case analysis of smart city initiatives, Information Technology for Development 23(3) (2017) 526-553. DOI: $10.1080 / 02681102.2017 .1353946$

[10] L. F. A. León, J. Rosen, Technology as ideology in urban governance, Annals of the American Association of Geographers 110(2) (2020) 497506.

DOI: https://doi.org/10.1080/24694452.2019.1660139

[11] J. Ojasalo, H. Kauppinen, Collaborative Innovation with External Actors: An Empirical 
Study on Open Innovation Platforms in Smart Cities, Technology Innovation Management Review 6(12) (2016) 49-60. http://timreview.ca/article/1041

[12] C. Coletta, R. Kitchin, Algorhythmic governance: Regulating the 'heartbeat' of a city using the Internet of Things, Big Data \& Society 4(2) (2017). DOI: https://doi.org/10.1177/2053951717742418

[13] M. Khan, M. Babar, S. H. Ahmed, S. C. Shah, K.Han, Smart city designing and planning based on big data analytics, Sustainable Cities and Society 35 (2017) 271-279. DOI: https://doi.org/10.1080/24694452.2019.1660139

[14] M. Babar, F. Arif, Smart urban planning using Big Data analytics to contend with the interoperability in Internet of Things, Future Generation Computer Systems 77 (2017) 65-76. DOI: https://doi.org/10.1016/j.future.2017.07.029

[15] A. Zanella, N. Bui, A. Castellani, L. Vangelista and M. Zorzi, Internet of Things for Smart Cities, IEEE Internet of Things Journal, 1(1) (2014) 2232. DOI: $10.1109 /$ JIOT.2014.2306328

[16] S. Joss, F. Sengers, D. Schraven, F. Caprotti, Y. Dayot, The smart city as global discourse: Storylines and critical junctures across 27 cities, Journal of Urban Technology 26(1) (2019) 3-34. DOI:

https://doi.org/10.1080/10630732.2018.1558387

[17] R. A., Amirov, E. V. Egorov, Digital economy and actual tasks of its personnel support in Russia, Management consulting 9 (117) (2018) 42-51 DOI10.22394/1726-1139-2018-9-42-50

[18] H. Jiang, S. Geertman, P. Witte, Smartening urban governance: An evidence-based perspective, Regional Science Policy \& Practice (2020). DOI: $10.1111 / \mathrm{rsp} 3.12304$

[19] Z. Tomor, A. Meijer, A. Michels, S. Geertman, Smart governance for sustainable cities: findings from a systematic literature review, Journal of Urban Technology 26(4) (2019) 3-27. DOI: https://doi.org/10.1080/10630732.2019.1651178

[20] Y. G. Lavrikova, I. A. Antipin, A. A.Pryadein, A. V.Suvorova, Major City Development Forecast: Designing the Innovative Future, Economic and Social Changes: Facts, Trends, Forecasts 6(48) (2016) 214-235. DOI: $10.15838 / \mathrm{esc} / 2016.6 .48 .12$
[21] Ya. P. Silin, Ye. B. Dvoryadkina, I. A. Antipin, The priorities of the strategic development of a new industrial city, Upravlenets, 9(6) (2018) 2 16. DOI: $10.29141 / 2218-5003-2018-9-6-1$

[22] Antipin, I. A. Megacity: formation and development in old industrial region, Upravlenets 5-6 (9-10) (2010) 24-31 